\title{
Role of Topoisomerase II $\beta$ in DNA Damage Response following IR and Etoposide
}

\author{
Nicola J. Sunter, Ian G. Cowell, Elaine Willmore, Gary P. Watters, and Caroline A. Austin
}

Institute for Cell and Molecular Biosciences, The Medical School, Newcastle University, Newcastle upon Tyne NE2 4HH, UK

Correspondence should be addressed to Caroline A. Austin, caroline.austin@ncl.ac.uk

Received 18 June 2010; Accepted 15 July 2010

Academic Editor: Ashis Basu

Copyright ( $) 2010$ Nicola J. Sunter et al. This is an open access article distributed under the Creative Commons Attribution License, which permits unrestricted use, distribution, and reproduction in any medium, provided the original work is properly cited.

The role of topoisomerase II $\beta$ was investigated in cell lines exposed to two DNA damaging agents, ionising radiation (IR) or etoposide, a drug which acts on topoisomerase II. The appearance and resolution of $\gamma \mathrm{H} 2 \mathrm{AX}$ foci in murine embryonic fibroblast cell lines, wild type and null for DNA topoisomerase II $\beta$, was measured after exposure to ionising radiation (IR) or etoposide. Topoisomerase II-DNA adduct levels were also measured. IR rapidly triggered phosphorylation of histone H2AX, less phosphorylation was seen in TOP $2 \beta^{-1-}$ cells, but the difference was not statistically significant. IR did not produce topoisomerase II-DNA adducts above control levels. Etoposide triggered the formation of topoisomerase II-DNA adducts and the phosphorylation of histone $\mathrm{H} 2 \mathrm{AX}$, the $\gamma \mathrm{H} 2 \mathrm{AX}$ foci appeared more slowly with etoposide than with IR. Topoisomerase II-DNA complexes in WT cells but not TOP $2 \beta^{-/-}$cells increased significantly at 24 hours with the proteasome inhibitor MG132, suggesting topoisomerase II $\beta$ adducts are removed by the proteasome.

\section{Introduction}

Exogenous agents such as ionising radiation (IR) and ultraviolet light or endogenous agents such as free radicals produced within cells can damage the DNA of eukaryotic organisms. Diverse mechanisms have evolved to detect and repair DNA damage that threatens the integrity of the genome. Here, we study two DNA damaging agents used in the treatment of cancer, IR and the epipodophyllotoxin drug etoposide that acts on topoisomerase II.

Cellular DNA damage responses to IR exposure have been extensively investigated and several pathways exist within the cell to respond to double strand breaks (DSBs) induced by ionising radiation (IR). Histone $\mathrm{H} 2 \mathrm{AX}$ is rapidly phosphorylated following IR, with foci observed within the first minute following exposure [1-3]. The phosphorylation of H2AX occurs over megabase regions of chromatin extending away from the site of DNA damage [1] and initiates assembly of several proteins involved in the DNA damage response [4]. H2AX phosphorylation has been shown to be essential for correct amplification of the DNA damage response [5-7]. At sublethal levels of DNA damage, phosphorylated $\mathrm{H} 2 \mathrm{AX}$ (termed $\gamma \mathrm{H} 2 \mathrm{AX}$ ) forms distinct foci within the cell nuclei. At less than 150 DSBs per nucleus, there exists a $1: 1$ relationship of $\gamma \mathrm{H} 2 \mathrm{AX}$ foci:DSBs [2]. At these levels of DNA damage, $\gamma \mathrm{H} 2 \mathrm{AX}$ can be used as an accurate and sensitive surrogate reporter of DNA DSB levels [8]. H2AX can also be phosphorylated in response to topoisomerase II-targeting agents [9-12].

Topoisomerase II is an enzyme that alters the topological state of DNA via a transient covalent enzyme-bridged double strand break in the DNA, through which a second DNA helix can pass. These protein associated breaks can be stabilised by drugs such as etoposide [13, 14]. Two isoforms of topoisomerase II exist, termed $\alpha$ and $\beta$ [15], these are both targeted by etoposide [16-18]. The genotoxic effects of etoposide are generally considered to be mediated through conversion of stabilised protein-DNA complexes to protein free "frank" DSBs $[19,20]$, possibly via collisions between the drug-stabilised topoisomerase-DNA complex and RNA polymerase during transcription or with DNA replication forks, analogous to the situation seen with topoisomerase I [21, 22]. Frank DSBs may also be generated by proteolytic degradation of the topoisomerase II moiety 

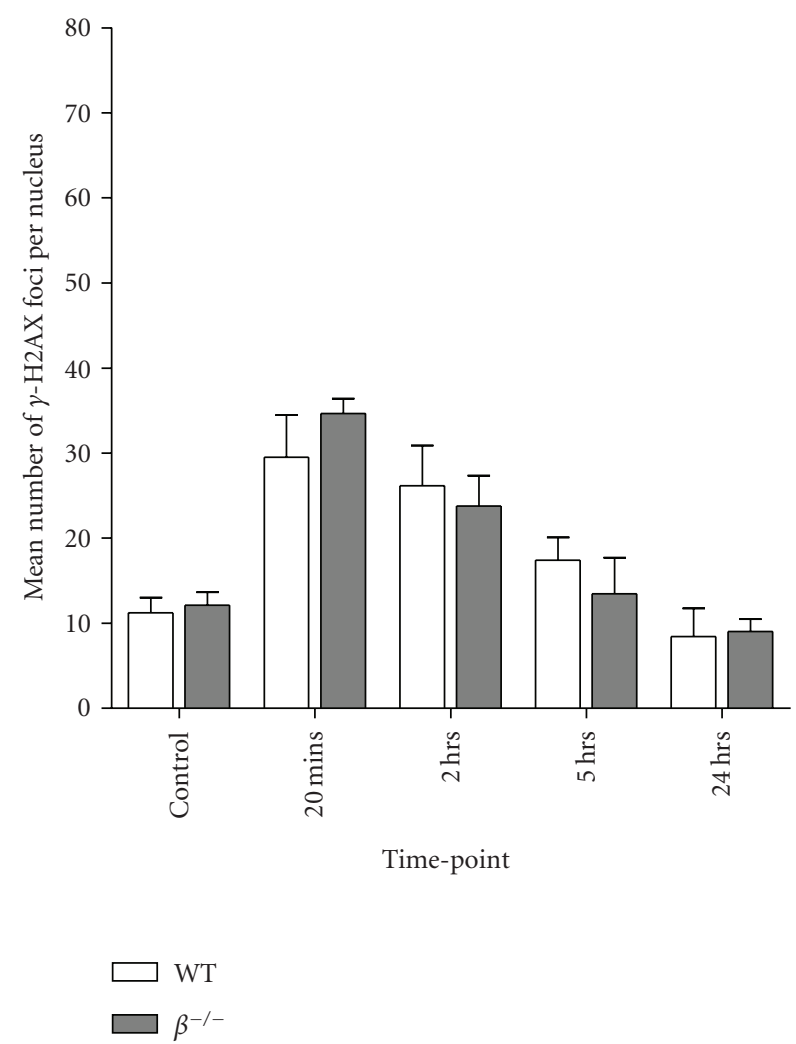

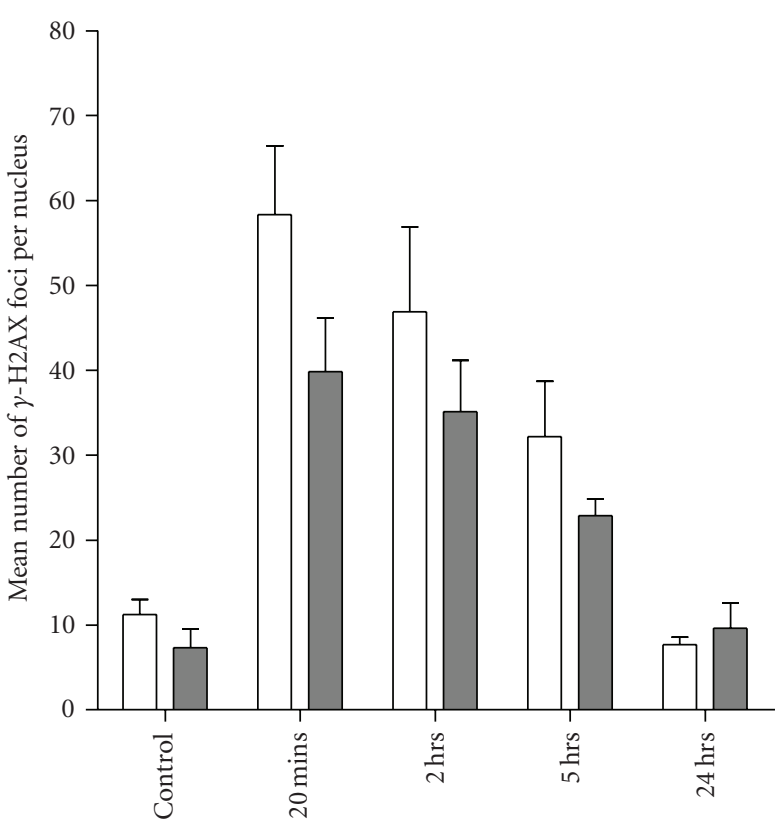

Time-point

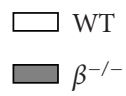

(a)

(b)

FIGURE 1: Effect of topoisomerase II $\beta$ status on $\gamma \mathrm{H} 2 \mathrm{AX}$ focus formation in response to IR. WT and TOP2 $\beta^{-/-}$MEFs were exposed to 1 Gy IR (a) or 2 Gy IR (b) and $\gamma \mathrm{H} 2 \mathrm{AX}$ foci were counted at 20 minutes, 2 hours, 5 hours, and 24 hours after exposure. Data are derived from at least $n=3$ independent experiments.

[23-26] and topoisomerase II $\beta$ is thought to be preferentially degraded over the $\alpha$ isoform [26]. A reduction in etoposide induced DSB levels was reported in cells cotreated with the proteasome inhibitor MG-132 [26], suggesting that the proteasome has a role in converting etoposide-stabilised protein-DNA complexes into frank DSBs [26]. Additionally a $5^{\prime}$ tyrosyl DNA phosphodiesterase (TTRAP) has recently been identified that may play a role in generating frank DSBs ready for repair [27].

Topoisomerase II has been implicated in the cellular response to DNA DSBs. Down regulating topoisomerase II $\alpha$ by siRNA altered the response to radiation [28] whilst topoisomerase II $\beta$ has been reported to play a role in promoting DSB repair following peroxide damage [29]. The damage sensor TopBP1 was first identified as a topoisomerase II $\beta$ interacting protein [30], and WSTF (Williams syndrome transcription factor) which regulates the H2AX DNA damage response [7] interacts with WINAC, a topoisomerase II $\beta$ containing multi protein complex [31]. Thus topoisomerase II $\beta$ may be directly involved in damage detection and signalling following IR via protein-protein interactions. Alternatively, topoisomerase II $\beta$ may be required for proper regulation of genes involved in the damage responses. For example, cells downregulated for topoisomerase II $\beta$ have been reported to express reduced peroxiredoxin 2 [32].
To investigate whether topoisomerase II $\beta$ affects the cellular response to IR or etoposide induced DNA damage, we used WT and TOP $2 \beta^{-/-}$MEFs, we used H2AX assays and in parallel the trapped in agarose DNA immunostaining (TARDIS) assay to examine the kinetics of formation and removal of topoisomerase II-DNA complexes in response to IR or etoposide treatment.

\section{Materials and Methods}

2.1. Cell Culture. Wild-type mTOP2 $\beta-4$ (containing both topoisomerase II $\alpha$ and topoisomerase II $\beta$ ) [WT] and mtop $2 \beta-5$ [TOP $\left.2 \beta^{-/-}\right]$immortalized mouse embryonic fibroblasts (MEFs) have been described previously [17] and were maintained as monolayers in Dulbecco's Modified Eagle's Medium (DMEM) supplemented with $10 \%$ foetal bovine serum (FBS) and penicillin $(50 \mu \mathrm{g} / \mathrm{mL}) /$ streptomycin $(50 \mu \mathrm{g} / \mathrm{mL})$. Cells were grown at $37^{\circ} \mathrm{C}$ in a humidified atmosphere containing $5 \% \mathrm{CO}_{2}$. Cell culture reagents were obtained from Gibco BRL (Paisley, UK).

2.2. Chemicals and DNA Damaging Agents. All chemicals were obtained from Sigma-Aldrich (Poole, UK) and VWR International (Lutterworth, UK). Etoposide was obtained 

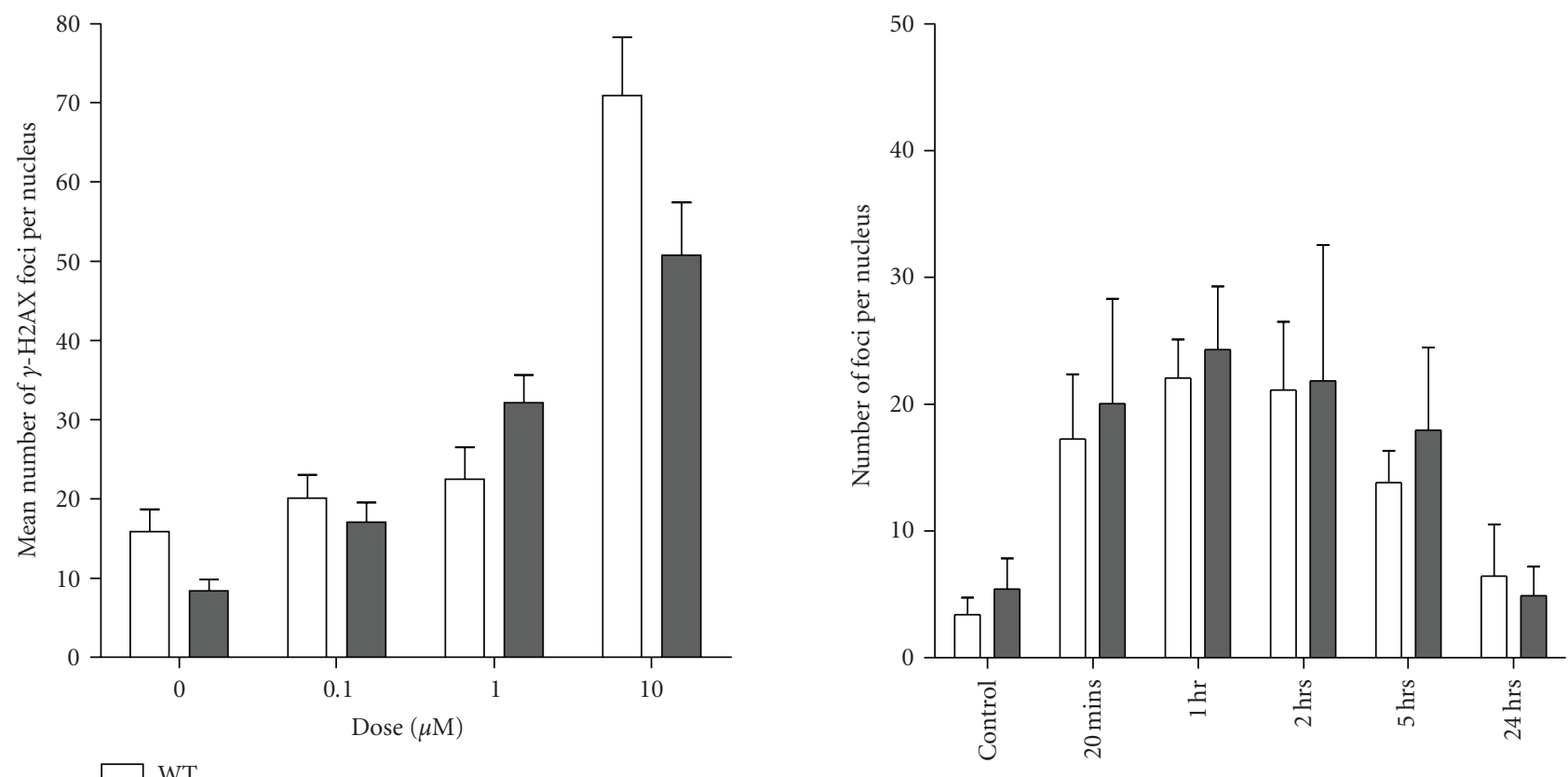

Time-point

(a)
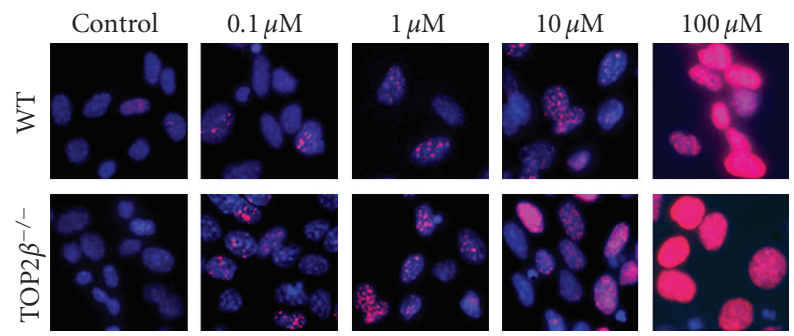

(b)

FIGURE 2: $\gamma \mathrm{H} 2 \mathrm{AX}$ foci formed in response to increasing doses of etoposide. WT and TOP $2 \beta^{-/-}$MEFs were exposed to $0.1,1,10$, and $100 \mu \mathrm{M}$ etoposide for 2 hours and then assayed for $\gamma \mathrm{H} 2 \mathrm{AX}$ foci. (a) Histograms of foci number \pm SEM at each dose counted. $100 \mu \mathrm{M}$ was not counted as foci were not distinct at this dose. Data derived from one experiment. (b) Representative images of $\gamma \mathrm{H} 2 \mathrm{AX}$ foci (red) in nuclei stained with DAPI (blue) in WT and TOP $2 \beta^{-/-}$ MEFs.

from Sigma and was dissolved in methanol. IR exposure was carried out using a Gammacell 1000 irradiator with a $\left[{ }^{137} \mathrm{Cs}\right]$ source (Nordion International, Inc.) and was delivered at a rate of approximately $3.08 \mathrm{~Gy} / \mathrm{min}$.

2.3. H2AX Focus Assay. The $\gamma \mathrm{H} 2 \mathrm{AX}$ focus assay was performed as described previously in detail by Watters and colleagues [12].

\subsection{TARDIS (Trapped in Agarose DNA Immunostaining).} WT and TOP $2 \beta^{-/-}$MEFs were seeded at $3 \times 10^{4}$ cells/well into 6-well tissue culture plates and grown to approximately $80 \%$ confluency. Cells were exposed to the appropriate DNA damaging agent (IR or etoposide) and harvested by trypsinisation at specific time-points as detailed in the text.
Trypsinised cells were resuspended in $1 \mathrm{~mL}$ of ice-cold PBS, centrifuged at $1000 \mathrm{rpm}$ for 3 minutes and then resuspended in $50 \mu \mathrm{L}$ of ice-cold PBS. The slide preparation has been described in detail previously [17]. Slides were probed with an antibody that detects topoisomerase II $\alpha$ and $\beta$.

Quantification of complex levels has been described previously [16]. Statistical analyses were carried out using Graphpad Prism 4 software (Cherwell Scientific, Oxford, UK.). Two-tailed, paired, and unpaired Students $t$-tests were generally used to compare data sets and data sets between cell lines; analysis of variance (ANOVA) was used for multiple comparisons where appropriate, as detailed in the text. All statistical analyses were calculated using a 95\% confidence interval $(P<.05)$.

\section{Results and Discussion}

The present study examined two DNA damaging agents, IR and etoposide. $\gamma \mathrm{H} 2 \mathrm{AX}$ formation was used as a surrogate marker for DSBs in parallel with topoisomerase II-DNA complex measurement in both wild-type and topoisomerase II $\beta$ null murine embryo fibroblast cell lines (MEFs).

The response to three doses of IR $(0.5,1$ and $2 \mathrm{~Gy})$ was determined in MEFs wild type (WT) or null for topoisomerase $\mathrm{II} \beta$ (TOP $2 \beta^{-/-}$). In response to $1 \mathrm{~Gy}, \gamma \mathrm{H} 2 \mathrm{AX}$ 


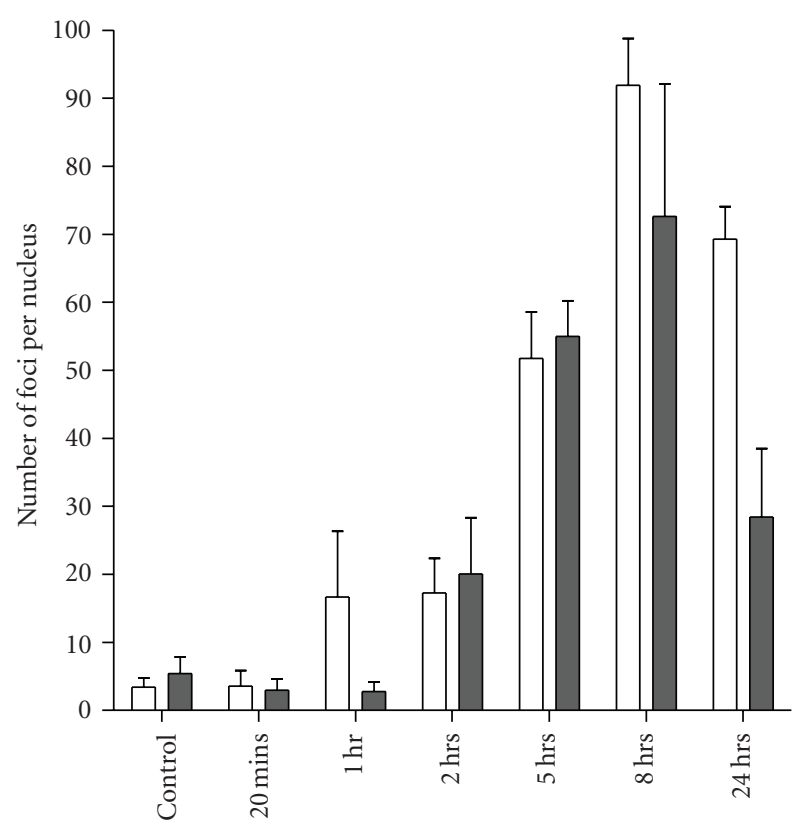

Time-point

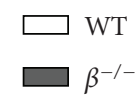

FIgure 4: $\gamma \mathrm{H} 2 \mathrm{AX}$ foci during continuous exposure to etoposide up to 24 hours. WT and TOP $2 \beta^{-/-}$MEFs were exposed to $1 \mu \mathrm{M}$ etoposide and $\gamma \mathrm{H} 2 \mathrm{AX}$ foci were counted at the indicated time points up to 24 hours. The data are derived from at least $n=3$ independent experiments, each data point shows the mean \pm SEM.

focus numbers were similar between the two cell lines, with $\sim 35 \gamma \mathrm{H} 2 \mathrm{AX}$ foci per nucleus at 20 minutes (Figure 1(a)). $\gamma \mathrm{H} 2 \mathrm{AX}$ foci were most abundant at the 20 minute timepoint after irradiation and decreased at each subsequent time-point investigated and returned to background levels at 24 hours (Figure 1(a)). Following 2 Gy (Figure 1(b)), focus numbers appeared higher in the WT cell line than the TOP $2 \beta^{-/-}$at 20 minutes, 2 hours, and 5 hours following exposure. The lower foci number in the TOP $2 \beta^{-1-}$ cells suggests the initial DNA damage responses following IR are altered in these cells, however, the differences were not statistically significant by two way ANOVA or Students $t$-test. Nor was there any significant difference between the levels of apoptosis following IR between the two cell lines. The trapped in agarose DNA immunostaining (TARDIS) assay was used to detect topoisomerase II protein-DNA complex levels in these cell lines following IR. Topoisomerase II complex formation did not increase in response to IR in WT or TOP $2 \beta^{-/-}$cells when compared to the untreated cells, as previously reported for CEM cells [18] (data not shown), thus IR had no effect upon topoisomerase II-DNA complex levels in the 24 hours following exposure to $2 \mathrm{~Gy}$.

In an etoposide "dose finding" experiment topoisomerase II $\beta$ wild-type and null MEF cell lines were exposed to $0,0.1,1,10$, or $100 \mu \mathrm{M}$ etoposide for 2 hours, after which time cells were placed in drug-free media for 20 minutes before being assayed for $\gamma \mathrm{H} 2 \mathrm{AX}$ foci. Foci numbers per nucleus increased in both cell lines with increasing dose of drug. At $100 \mu \mathrm{M}$, foci were no longer distinct and therefore uncountable (Figure 2). To ensure foci were within a countable range, subsequent experiments were performed using doses of $1 \mu \mathrm{M}$ and $10 \mu \mathrm{M}$ only.

WT and TOP $2 \beta^{-/-}$cells were exposed to $1.0 \mu \mathrm{M}$ etoposide for 2 hours, cells were then resuspended in drugfree media and assayed for $\gamma \mathrm{H} 2 \mathrm{AX}$ at different time points after drug removal, 20 minutes, 2 hours, 5 hours, and 24 hours following removal of drug (Figure 3 ). The kinetics of focus formation and removal were comparable between the wild-type and TOP $2 \beta^{-/-}$cell lines, and by 24 hours postdrug removal foci numbers were similar to untreated controls. No statistically significant difference was found in focus numbers between the two cell lines, indicating that topoisomerase II $\beta$ status did not affect the kinetics of disappearance of $\gamma \mathrm{H} 2 \mathrm{AX}$ phosphorylation following a 2 hour exposure to $1 \mu \mathrm{M}$ etoposide, this is consistent with the evidence that the cytotoxic effect of etoposide is mainly mediated via topoisomerase II $\alpha$ in these cells, since the IC50 for etoposide did not differ significantly between the two cell lines [17]. The topoisomerase II-DNA adducts levels measured by TARDIS after a 2 hour exposure to etoposide has previously been reported [17].

Wild-type and TOP $2 \beta^{-/-}$cells were also exposed continuously to $1.0 \mu \mathrm{M}$ etoposide over the course of 24 hours, and samples removed to quantify $\gamma \mathrm{H} 2 \mathrm{AX}$ foci formation at various time points (Figure 4). After two hours of etoposide exposure the foci numbers were comparable to that seen after the two-hour short term exposure, numbers then increased further with continued exposure to etoposide. The maximal foci numbers were seen after 8 hours of etoposide, and they then decreased by 24 hours even though etoposide was still present. The focus numbers were statistically different between the two cell lines only at the 24 hours point $(P<.05)$, when the WT cell line had approximately double the number of foci compared to the TOP $2 \beta^{-/-}$cell line.

Topoisomerase II-DNA complex levels in WT and TOP $2 \beta^{-/-}$cells were determined using the TARDIS assay at time-points over a 24 hour continuous exposure to etoposide at $1 \mu \mathrm{M}$ (Figure 5(a)) or $10 \mu \mathrm{M}$ (Figure 5(b)). At both drug doses and in both cell lines, treatment induced a time-dependent increase in topoisomerase II DNA adduct levels (FITC immunofluorescence) up to the 8 hour timepoint followed by a decrease at the 24 hour time-point (Figures 5(a) and 5(b)). With $1 \mu \mathrm{M}$ etoposide, the increase was significant at 8 hours in WT cells and at both 5 hours $(P<.05)$ and 8 hours $(P<.01)$ in TOP $2 \beta^{-1-}$ cells. Although levels decreased at 24 hours, immunofluorescence was still significantly greater than background levels in both wildtype and TOP $2 \beta^{-/-}$cells $(P<.05)$. When cells were exposed to $10 \mu \mathrm{M}$ etoposide, immunofluorescence levels in WT cells became statistically significant at 2 hours after drug addition $(P<.05)$ and remained elevated at all other time-points $(P<$ $.01)$. In TOP $2 \beta^{-1-}$ cells, levels were significant at 1 hour $(P<$ $.01)$, 5 hours $(P<.05)$, and 24 hours $(P<.001)$. Notably immunofluorescence levels were greater in the TOP $2 \beta^{-/-}$ 


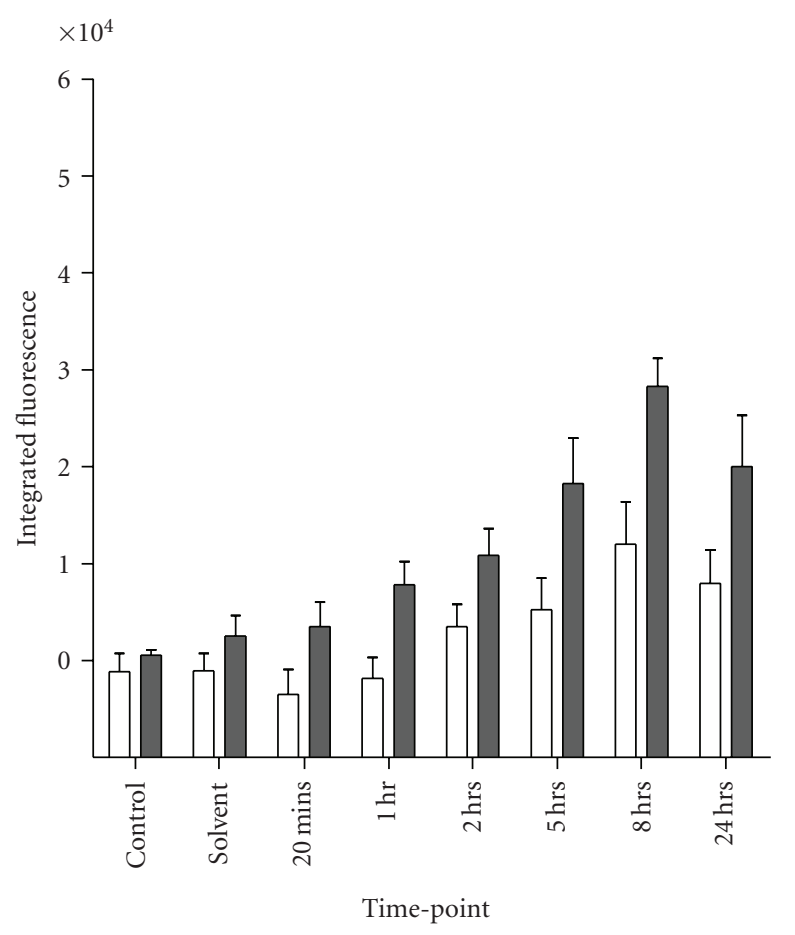

$\square \mathrm{WT}$
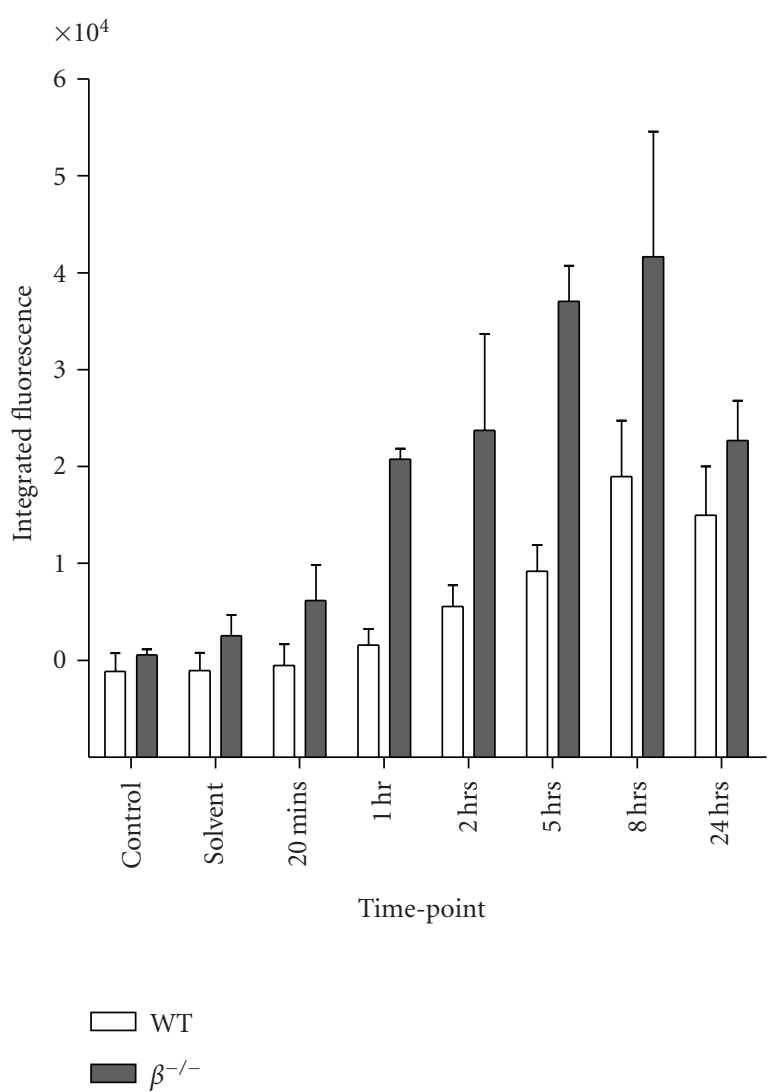

(a)

(b)

FIGURE 5: TARDIS analysis of cells treated with etoposide continuously for 24 hours. Topoisomerase II-DNA adducts were detected using an antibody that detects both isoforms in WT and TOP $2 \beta^{-/-}$MEFs following exposure to $1 \mu \mathrm{M}$ (a) or $10 \mu \mathrm{M}$ (b). Plots show the mean of the median FITC fluorescence from at least three independent experiments.

cells than the wild-type cells (Figure 5) at both drug doses and all time-points (all $P$-values <.05). The higher complex levels seen in cells lacking topoisomerase II $\beta$ may result from the longer half life of topoisomerase II $\alpha$ complexes [16] or be due to a role of topoisomerase II $\beta$ in sensing and/or promoting repair [29] or alternatively to downregulation of peroxiredoxins in TOP $2 \beta^{-/-}$cells $[32,33]$.

To investigate whether the decrease in topoisomerase IIDNA complexes between the 8 hour and 24 hour time-points was due to proteasomal degradation of topoisomerase II, WT and TOP $2 \beta^{-/-}$cells were incubated in the presence of the proteasome inhibitor, MG-132, for 30 minutes prior to and during 24 hour exposures to $1 \mu \mathrm{M}$ and $10 \mu \mathrm{M}$ etoposide. As shown in Figure 6(e), when treated with MG-132 alone, topoisomerase II-DNA complex levels were only significantly elevated above background levels at the 24 hour time-point. Immunofluorescence levels were comparable in the WT and TOP $2 \beta^{-1-}$ cells at all time-points considered. In cells cotreated with etoposide and MG-132, topoisomerase IIDNA complex levels did not decrease between the 8 hour and 24 hour time-points, as seen in cells treated with etoposide alone. Figure 6(a)-6(d), demonstrate that cotreatment led to increased immunofluorescence at the 24 hour time-point, in both cell lines and at both drug doses. This increase was most dramatic in WT cells, where cotreatment led to a 6-fold increase in immunofluorescence in cells treated with $1 \mu \mathrm{M}$ etoposide and a 15 -fold increase in cells treated with $10 \mu \mathrm{M}$ etoposide. In the TOP $2 \beta^{-/-}$cells, the increase was roughly 2fold at both doses of drug. This indicates that topoisomerase II removal at 24 hours is mediated via the proteasome, and that the effect is greatest on topoisomerase II $\beta$, in agreement with previous studies $[23,25,26]$.

\section{Conclusions}

In response to IR phosphorylation of histone H2AX was triggered immediately, and slightly less phosphorylation was seen in TOP $2 \beta^{-/-}$cells, which may indicate altered DNA damage sensing. As previously reported, IR did not produce topoisomerase II-DNA adducts. In response to etoposide both $\gamma \mathrm{H} 2 \mathrm{AX}$ foci and topoisomerase II-DNA adducts were formed, with foci appearing 1 hour after treatment in WT cells and after 2 hours in TOP $2 \beta^{-/-}$cells. This was slower than following treatment with IR, and presumably reflects the need to remove the topoisomerase II adduct to produce a frank DSB to trigger phosphorylation of histone H2AX. In both instances, levels become maximal at the 8 hour timepoint and subsequently decrease at 24 hours. 

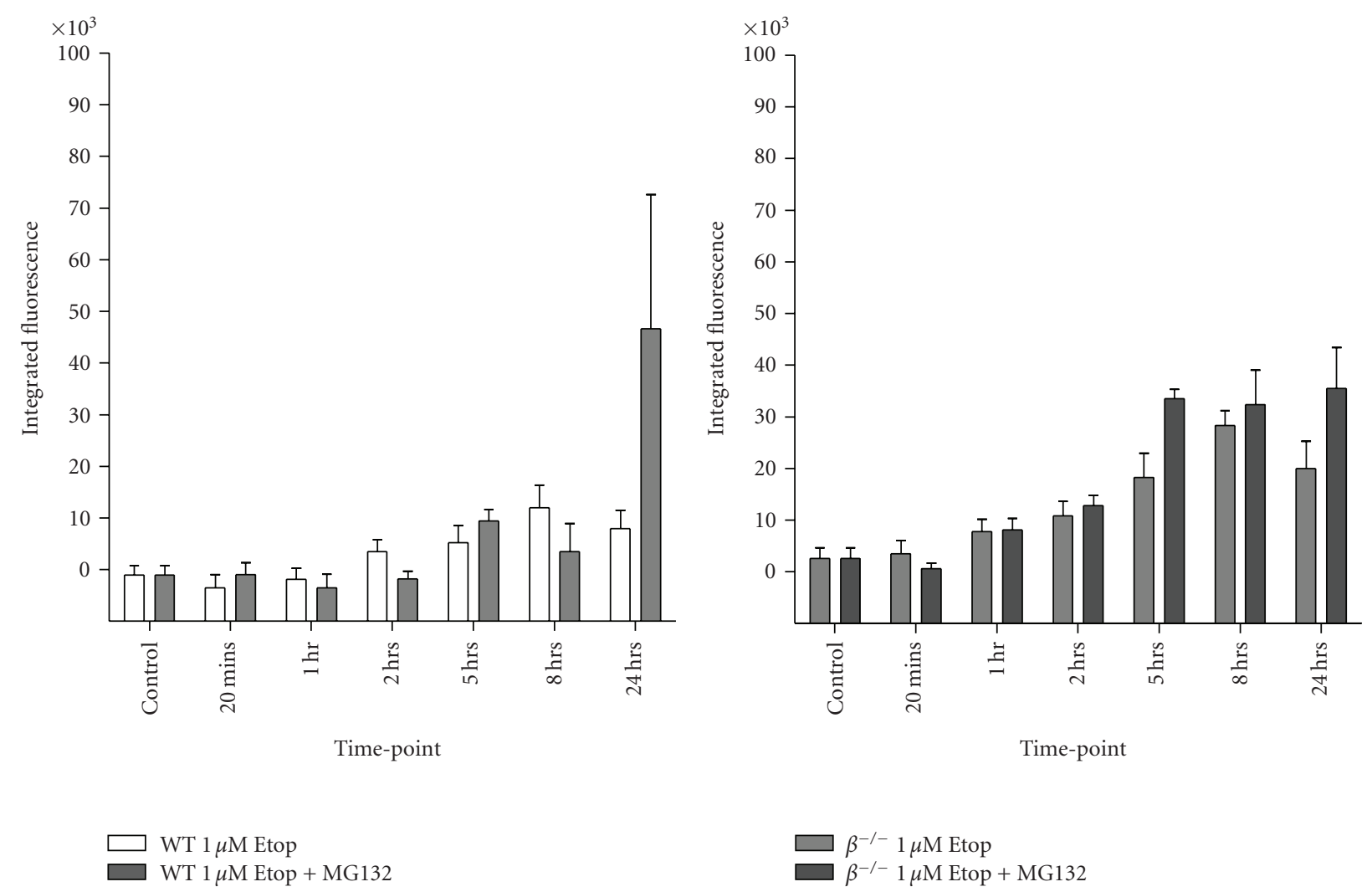

(a)

(b)

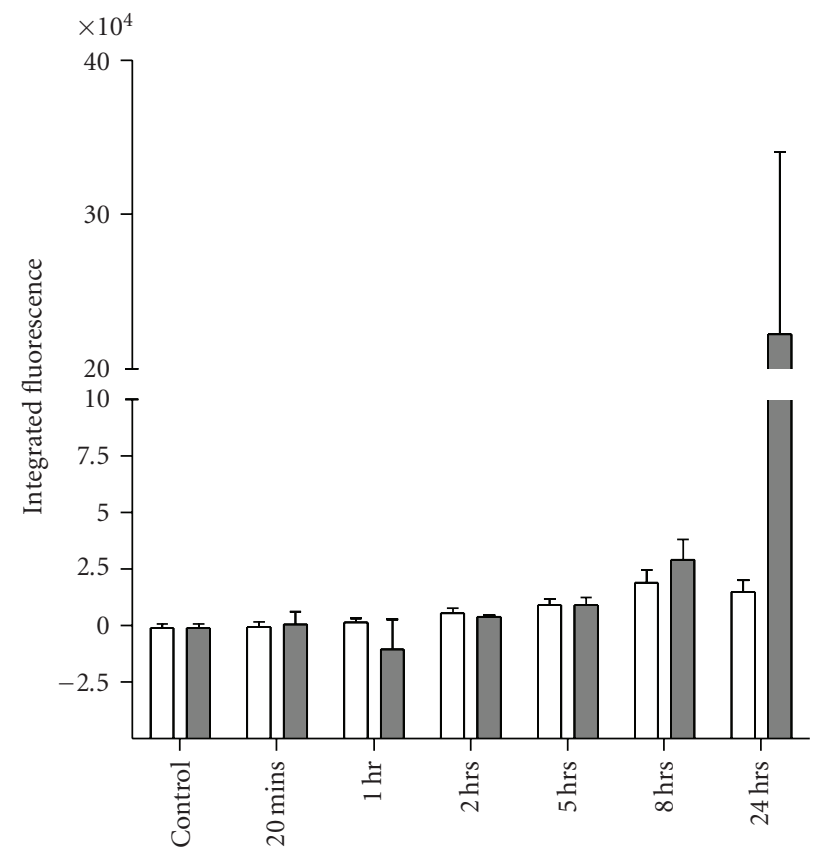

Time-point

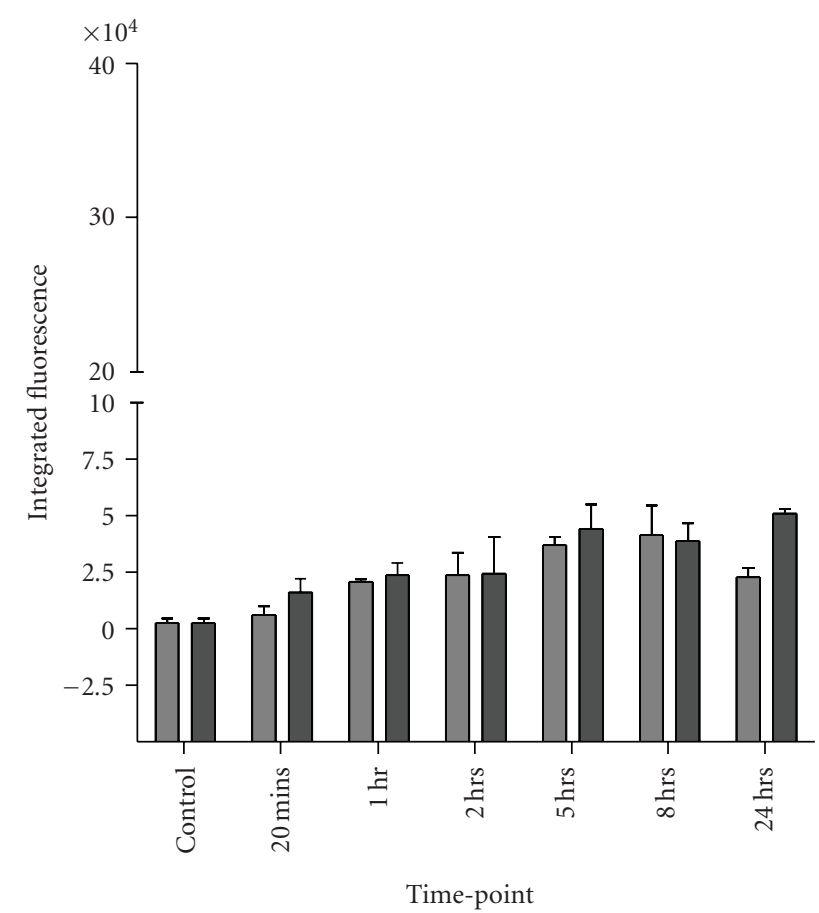

(c)

(d)

Figure 6: Continued. 


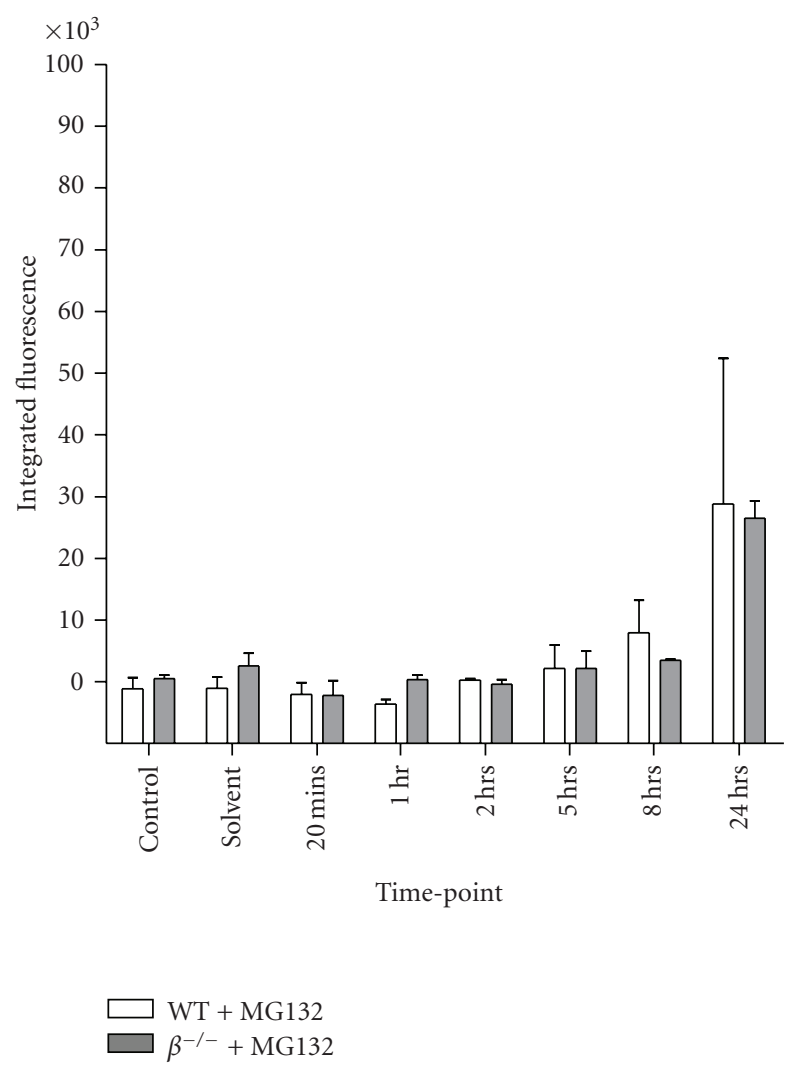

(e)

FIGURE 6: TARDIS analysis of cells treated with etoposide continuously for 24 hours plus and minus MG132 or with MG132 alone. Topoisomerase II-DNA adducts were quantified using an antibody that detects both isoforms. WT MEFs following exposure to $1 \mu \mathrm{M} \pm$ $2 \mu \mathrm{M}$ MG132 (a), Top2 $\beta^{-/-}$MEFs following exposure to $1 \mu \mathrm{M} \pm 2 \mu \mathrm{M}$ MG132 (b), WT MEFs following exposure to $10 \mu \mathrm{M} \pm 2 \mu \mathrm{M}$ MG132 (c), Top $2 \beta^{-/-}$MEFs following exposure to $10 \mu \mathrm{M} \pm 2 \mu \mathrm{M}$ MG132 (d), or WT and TOP $2 \beta^{-/-}$MEFs following exposure to $2 \mu \mathrm{M}$ MG132 alone (e). Plots show the mean of the median FITC fluorescence.

Topoisomerase II complexes in WT cells but not TOP $2 \beta^{-/-}$cells increased significantly at 24 hours when the proteasome was inhibited, suggesting that topoisomerase II $\beta$ adducts are removed by the proteasome.

\section{Acknowledgment}

N. J. Sunter was funded on an LRF Gordon Pillar Studentship, now the LLR.

\section{References}

[1] E. P. Rogakou, C. Boon, C. Redon, and W. M. Bonner, "Megabase chromatin domains involved in DNA doublestrand breaks in vivo," Journal of Cell Biology, vol. 146, no. 5, pp. 905-915, 1999.

[2] E. P. Rogakou, D. R. Pilch, A. H. Orr, V. S. Ivanova, and W. M. Bonner, "DNA double-stranded breaks induce histone H2AX phosphorylation on serine 139," Journal of Biological Chemistry, vol. 273, no. 10, pp. 5858-5868, 1998.

[3] C. H. Bassing, K. F. Chua, J. Sekiguchi et al., "Increased ionizing radiation sensitivity and genomic instability in the absence of histone H2AX," Proceedings of the National Academy of
Sciences of the United States of America, vol. 99, no. 12, pp. 8173-8178, 2002.

[4] M. Stucki and S. P. Jackson, " $\gamma \mathrm{H} 2 \mathrm{AX}$ and MDC1: anchoring the DNA-damage-response machinery to broken chromosomes," DNA Repair, vol. 5, no. 5, pp. 534-543, 2006.

[5] A. Celeste, S. Petersen, P. J. Romanienko et al., "Genomic instability in mice lacking histone H2AX," Science, vol. 296, no. 5569, pp. 922-927, 2002.

[6] I. G. Cowell, N. J. Sunter, P. B. Singh, C. A. Austin, B. W. Durkacz, and M. J. Tilby, " $\gamma \mathrm{H} 2 \mathrm{AX}$ foci form preferentially in euchromatin after ionising-radiation," PLOS ONE, vol. 2, no. 10, article e1057, 2007.

[7] A. Xiao, H. Li, D. Shechter et al., "WSTF regulates the H2A.X DNA damage response via a novel tyrosine kinase activity," Nature, vol. 457, no. 7225, pp. 57-62, 2009.

[8] F. Bouquet, C. Muller, and B. Salles, "The loss of $\gamma \mathrm{H} 2 \mathrm{AX}$ signal is a marker of DNA double strand breaks repair only at low levels of DNA damage," Cell Cycle, vol. 5, no. 10, pp. 11161122, 2006.

[9] X. Huang, F. Traganos, and Z. Darzynkiewicz, "DNA damage induced by DNA topoisomerase I- and topoisomerase IIinhibitors detected by histone $\mathrm{H} 2 \mathrm{AX}$ phosphorylation in relation to the cell cycle phase and apoptosis," Cell cycle (Georgetown, Tex.), vol. 2, no. 6, pp. 614-619, 2003. 
[10] J. P. Banáth and P. L. Olive, "Expression of phosphorylated histone $\mathrm{H} 2 \mathrm{AX}$ as a surrogate of cell killing by drugs that create DNA double-strand breaks," Cancer Research, vol. 63, no. 15, pp. 4347-4350, 2003.

[11] D. J. Smart, H. D. Halicka, G. Schmuck, F. Traganos, Z. Darzynkiewicz, and G. M. Williams, "Assessment of DNA double-strand breaks and $\gamma \mathrm{H} 2 \mathrm{AX}$ induced by the topoisomerase II poisons etoposide and mitoxantrone," Mutation Research, vol. 641, no. 1-2, pp. 43-47, 2008.

[12] G. P. Watters, D. J. Smart, J. S. Harvey, and C. A. Austin, "H2AX phosphorylation as a genotoxicity endpoint," Mutation Research, vol. 679, no. 1-2, pp. 50-58, 2009.

[13] J. M. Fortune and N. Osheroff, "Topoisomerase II as a target for anticancer drugs: when enzymes stop being nice," Progress in Nucleic Acid Research and Molecular Biology, vol. 64, pp. 221-253, 2000.

[14] A. C. G. Porter and C. J. Farr, "Topoisomerase II: untangling its contribution at the centromere," Chromosome Research, vol. 12, no. 6, pp. 569-583, 2004.

[15] C. A. Austin and K. L. Marsh, "Eukaryotic DNA topoisomerase II $\beta$," BioEssays, vol. 20, no. 3, pp. 215-226, 1998.

[16] F. Errington, E. Willmore, C. Leontiou, M. J. Tilby, and C. A. Austin, "Differences in the longevity of topo II $\alpha$ and topo II $\beta$ drug-stabilized cleavable complexes and the relationship to drug sensitivity," Cancer Chemotherapy and Pharmacology, vol. 53, no. 2, pp. 155-162, 2004.

[17] F. Errington, E. Willmore, M. J. Tilby et al., "Murine transgenic cells lacking DNA topoisomerase II $\beta$ are resistant to acridines and mitoxantrone: analysis of cytotoxicity and cleavable complex formation," Molecular Pharmacology, vol. 56, no. 6, pp. 1309-1316, 1999.

[18] E. Willmore, A. J. Frank, K. Padget, M. J. Tilby, and C. A. Austin, "Etoposide targets topoisomerase II $\alpha$ and II $\beta$ in leukemic cells: isoform-specific cleavable complexes visualized and quantified in situ by a novel immunofluorescence technique," Molecular Pharmacology, vol. 54, no. 1, pp. 78-85, 1998.

[19] K. Caldecott, G. Banks, and P. Jeggo, "DNA double-strand break repair pathways and cellular tolerance to inhibitors of topoisomerase II," Cancer Research, vol. 50, no. 18, pp. 57785783, 1990.

[20] S. H. Kaufmann, "Cell death induced by topoisomerasetargeted drugs: more questions than answers," Biochimica et Biophysica Acta, vol. 1400, no. 1-3, pp. 195-211, 1998.

[21] J. Wu and L. F. Liu, "Processing of topoisomerase I cleavable complexes into DNA damage by transcription," Nucleic Acids Research, vol. 25, no. 21, pp. 4181-4186, 1997.

[22] Y.-H. Hsiang, M. G. Lihou, and L. F. Liu, "Arrest of replication forks by drug-stabilized topoisomerase I-DNA cleavable complexes as a mechanism of cell killing by camptothecin," Cancer Research, vol. 49, no. 18, pp. 5077-5082, 1989.

[23] A. M. Azarova, Y. L. Lyu, C.-P. Lin et al., "Roles of DNA topoisomerase II isozymes in chemotherapy and secondary malignancies," Proceedings of the National Academy of Sciences of the United States of America, vol. 104, no. 26, pp. 1101411019, 2007.

[24] Y. Mao, S. D. Desai, C.-Y. Ting, J. Hwang, and L. F. Liu, "26 S proteasome-mediated degradation of topoisomerase II cleavable complexes," Journal of Biological Chemistry, vol. 276, no. 44, pp. 40652-40658, 2001.

[25] H. Xiao, Y. Mao, S. D. Desai et al., "The topoisomerase II $\beta$ circular clamp arrests transcription and signals a $26 \mathrm{~S}$ proteasome pathway," Proceedings of the National Academy of Sciences of the United States of America, vol. 100, no. 6, pp. 3239-3244, 2003.

[26] A. Zhang, Y. L. Lyu, C.-P. Lin et al., "A protease pathway for the repair of topoisomerase II-DNA covalent complexes," Journal of Biological Chemistry, vol. 281, no. 47, pp. 35997-36003, 2006.

[27] F. C. Ledesma, S. F. El Khamisy, M. C. Zuma, K. Osborn, and K. W. Caldecott, "A human 5'-tyrosyl DNA phosphodiesterase that repairs topoisomerase-mediated DNA damage," Nature, vol. 461, no. 7264, pp. 674-678, 2009.

[28] S. Y. A. Terry, A. C. Riches, and P. E. Bryant, "Suppression of topoisomerase II $\alpha$ expression and function in human cells decreases chromosomal radiosensitivity," Mutation Research, vol. 663, no. 1-2, pp. 40-45, 2009.

[29] R. K. Mandraju, P. Kannapiran, and A. K. Kondapi, “Distinct roles of Topoisomerase II isoforms: DNA damage accelerating $\alpha$, double strand break repair promoting $\beta$," Archives of Biochemistry and Biophysics, vol. 470, no. 1, pp. 27-34, 2008.

[30] K. Yamane, M. Kawabata, and T. Tsuruo, "A DNAtopoisomerase-II-binding protein with eight repeating regions similar to DNA-repair enzymes and to a cell-cycle regulator," European Journal of Biochemistry, vol. 250, no. 3, pp. 794-799, 1997.

[31] H. Kitagawa, R. Fujiki, K. Yoshimura et al., "The chromatinremodeling complex WINAC targets a nuclear receptor to promoters and is impaired in Williams syndrome," Cell, vol. 113, no. 7, pp. 905-917, 2003.

[32] K. Chikamori, J. E. Hill, D. R. Grabowski et al., "Downregulation of topoisomerase II $\beta$ in myeloid leukemia cell lines leads to activation of apoptosis following all-trans retinoic acidinduced differentiation/growth arrest," Leukemia, vol. 20, no. 10, pp. 1809-1818, 2006.

[33] A. V. Kropotov, P. S. Grudinkin, N. M. Pleskach, B. A. Gavrilov, N. V. Tomilin, and B. Zhivotovsky, "Downregulation of peroxiredoxin $\mathrm{V}$ stimulates formation of etoposide-induced double-strand DNA breaks," FEBS Letters, vol. 572, no. 1-3, pp. 75-79, 2004. 

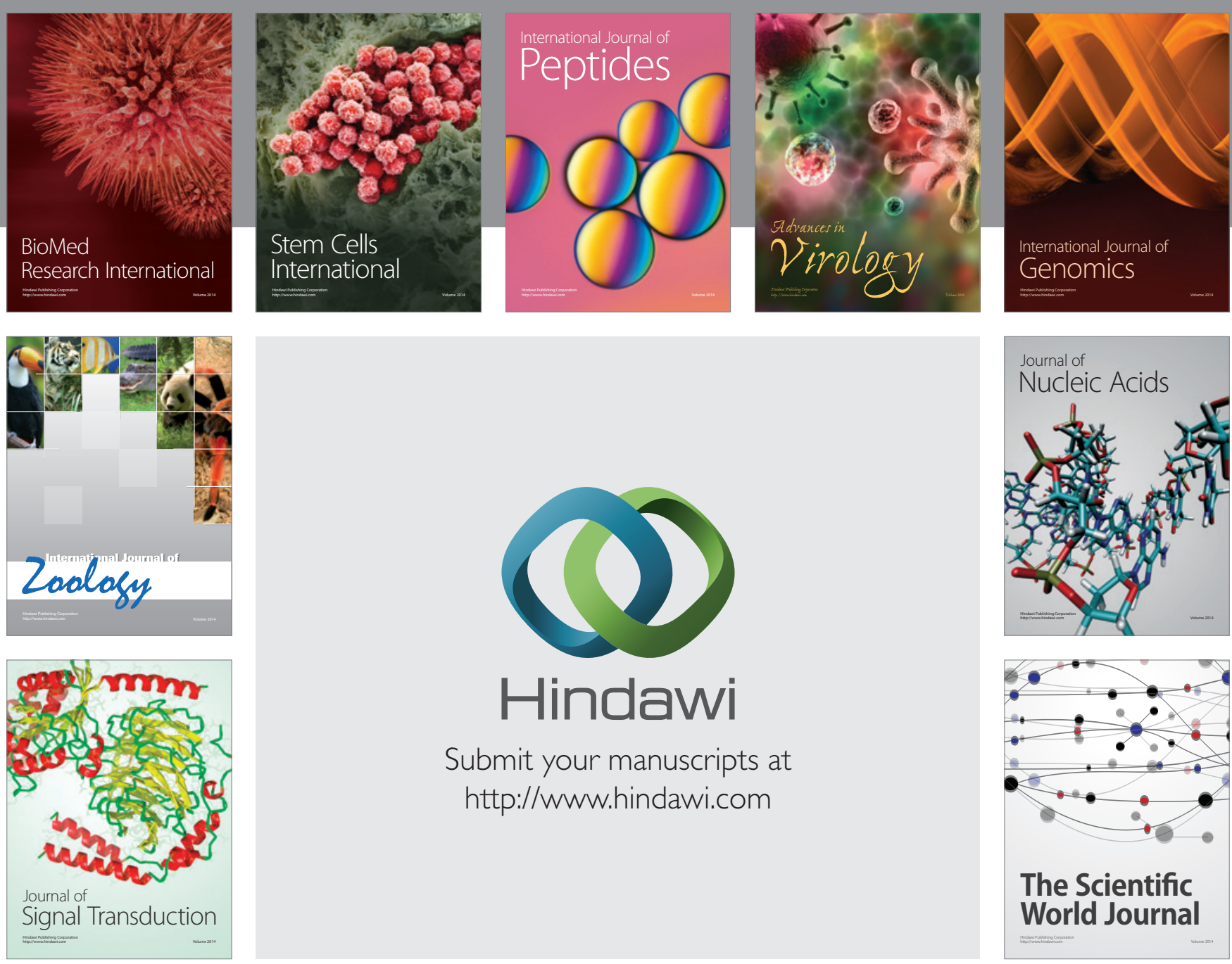

Submit your manuscripts at

http://www.hindawi.com
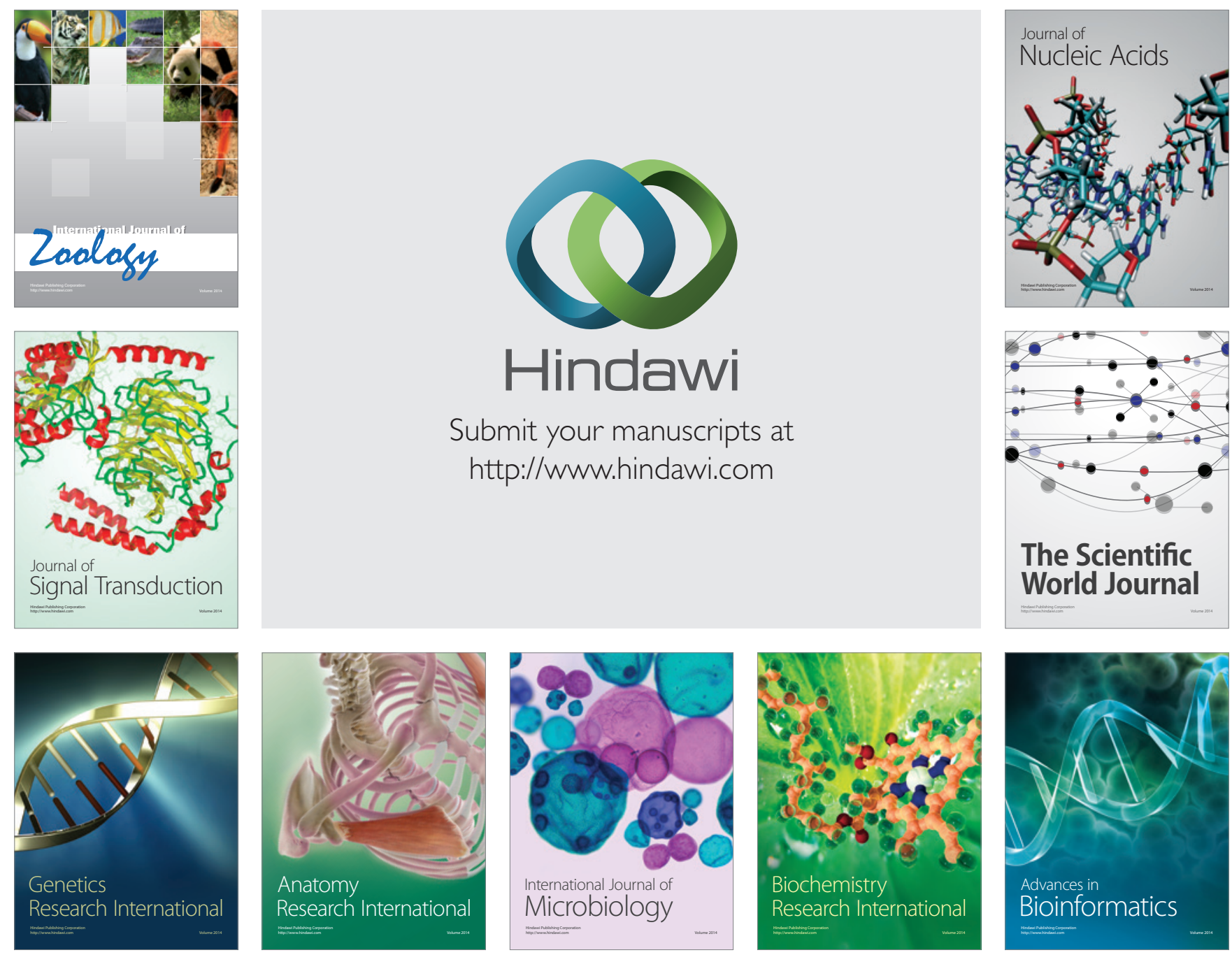

The Scientific World Journal
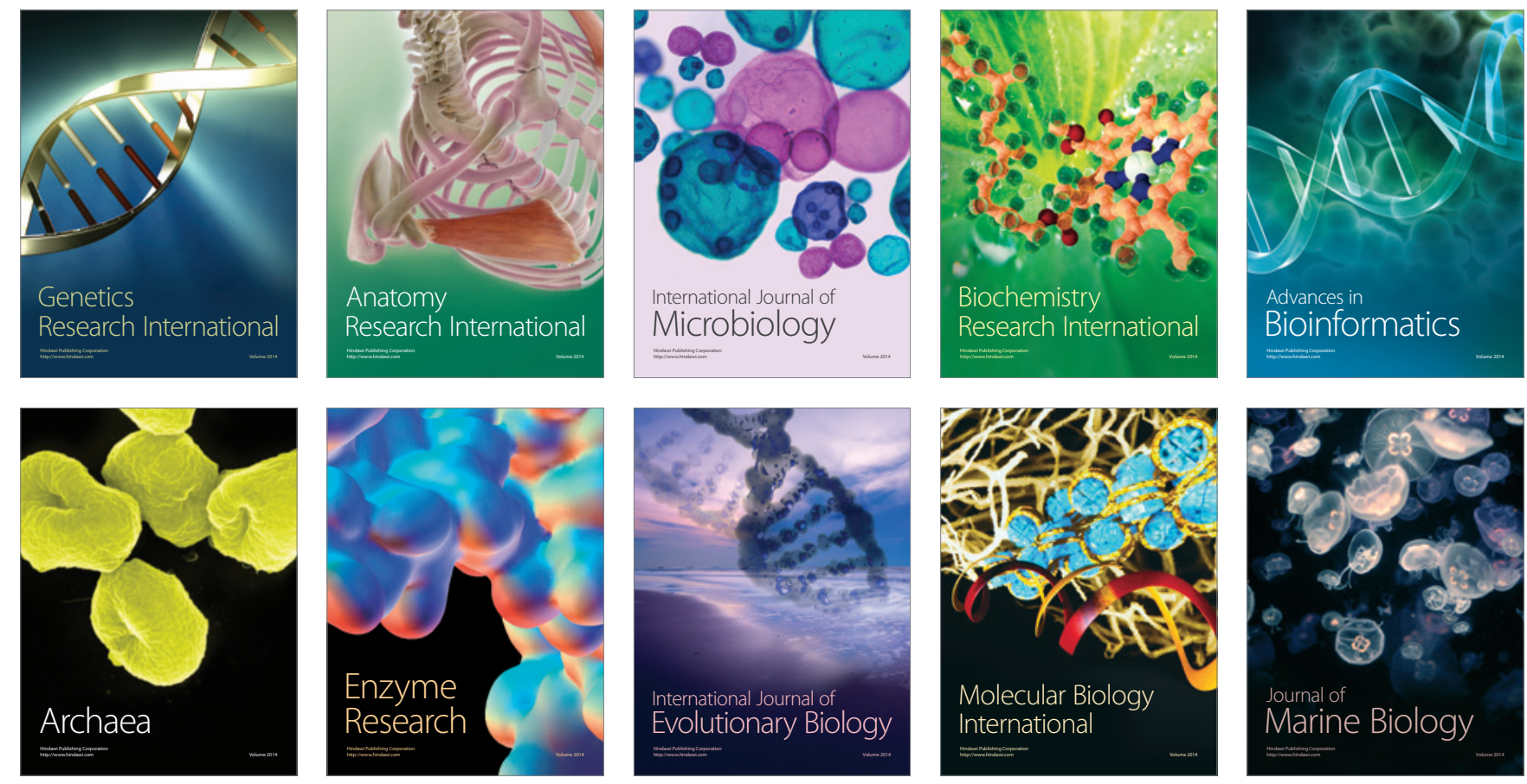